\title{
La Bourgogne, dernier des royaumes carolingiens (855-1056). Rois, pouvoirs et élites autour du Léman
}

\section{François Demotz}

\section{(2) OpenEdition} Journals

Édition électronique

URL : https://journals.openedition.org/cem/11182

DOI : $10.4000 /$ cem. 11182

ISSN : 1954-3093

Éditeur

Centre d'études médiévales Saint-Germain d'Auxerre

Édition imprimée

Date de publication : 15 août 2009

Pagination : 407-409

ISSN : $1623-5770$

\section{Référence électronique}

François Demotz, «La Bourgogne, dernier des royaumes carolingiens (855-1056). Rois, pouvoirs et élites autour du Léman », Bulletin du centre d'études médiévales d'Auxerre | BUCEMA [En ligne], 13 | 2009, mis en ligne le 09 septembre 2009, consulté le 22 septembre 2022. URL : http:// journals.openedition.org/cem/11182; DOI : https://doi.org/10.4000/cem.11182

Ce document a été généré automatiquement le 22 septembre 2022.

\section{c) (1) (2)}

Creative Commons - Attribution - Pas d'Utilisation Commerciale - Partage dans les Mêmes Conditions 4.0 International - CC BY-NC-SA 4.0

https://creativecommons.org/licenses/by-nc-sa/4.0/ 


\title{
La Bourgogne, dernier des royaumes carolingiens (855-1056). Rois, pouvoirs et élites autour du Léman
}

\author{
François Demotz
}

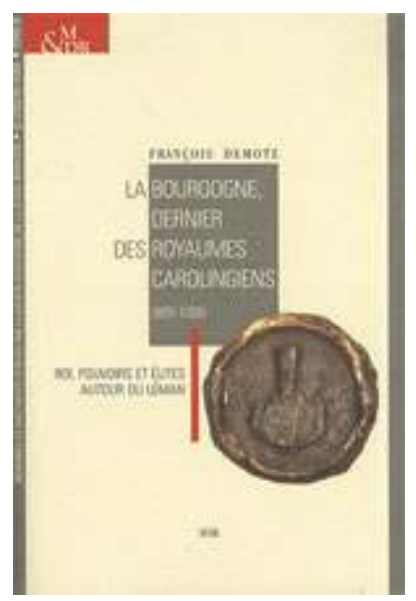

À l'échelon de l'Occident médiéval, la Bourgogne transjurane pourrait n'être qu'une petite région périphérique, avec ses trois diocèses, Genève, Lausanne et Sion, enclavés entre de puissants massifs montagneux, le Jura et les Alpes. Entité incongrue à l'heure des États nations, elle a vu son histoire négligée, à l'exception des synthèses de René Poupardin au temps des grandes études carolingiennes. Toutefois, depuis une trentaine d'années, l'édition des actes des rois de Bourgogne, de nouvelles études suisses sur la Burgondie et les régions romandes ainsi que le renouvellement de la compréhension des élites ont puissamment contribué à faire évoluer la perception de l'histoire transjurane. Débarrassée d'un avenir forcément national ou impérial, la Transjurane des IX ${ }^{\mathrm{e}}$ $\mathrm{XI}^{\mathrm{e}}$ siècles peut être étudiée en tant que telle, c'est-à-dire comme un espace politique de son temps à la charnière de beaucoup d'autres. 
2 La Bourgogne Transjurane est un objet d'étude unique. Seule zone de l'ancienne Lotharingie qui survive comme royaume, elle se situe entre trois grands ensembles politiques, France, Germanie et Italie, dont elle reçoit les influences. Espace particulier sur le plan géographique, elle l'est surtout du fait de la chronologie : c'est la seule partie du monde carolingien qui soit constamment aux mains de la même famille de 864 à 1032. Elle est donc proprement postcarolingienne : les structures et les hommes peuvent perdurer, sans les ruptures qui affectent la Germanie ou l'Italie et sans les Carolingiens qui retrouvent le trône en France. Ainsi, la Transjurane permet non seulement de porter un nouveau regard sur le devenirdes structures et des élites carolingiennes, sujet qui divise l'historiographie, mais aussi d'envisager un très large $x^{e}$ siècle comme autre chose qu'un temps de transition. L'histoire du royaume de Bourgogne dessine alors deux périodes assez différentes.

3 La première période est celle du royaume carolingien tardif. Jusqu'aux années 930, le royaume de Bourgogne est une monarchie de continuité où s'exerce un pouvoir carolingien, mais sans Carolingien et à une échelle réduite. La mort de Charles le Gros en 888 a permis à ses représentants privilégiés dans un regnum, ici les Welfs-Rodolphiens, de transformer leur prééminence régionale en royauté : le marquis-comte-abbé de Saint-Maurice d'Agaune se veut, là comme ailleurs, l'héritier naturel du dernier empereur carolingien. Après avoir manqué de s'étendre en Lorraine puis de disparaître, le nouveau royaume de Bourgogne est vers 900 une réduction de l'empire disparu. Les élites présentent des caractères nettement carolingiens comme la mobilité - même si les migrations se font plus modestes -, la famille large, les liens horizontaux ou l'importance de l'accès au roi. Celui-ci reste le distributeur de l'autorité et fait perdurer les pratiques administratives. Le gouvernement est d'abord celui d'un roi proche, appuyé sur quelques grands laïcs et jaloux de ses droits, notamment vis-à-vis de l'Église. Ce système, qui rappelle l'ancienne Francie orientale d'où sont issus les Welfs, est suffisamment souple et bien rodé pour fournir ensuite une solide base d'expansion.

4 C'est autour de 940 que disparaît le royaume carolingien tardif. La première cause en est la minorité du roi Conrad qui aboutit à une dépendance envers Otton $\mathrm{I}^{\text {er }}$ et une aggravation des raids païens. La seconde réside dans la croissance territoriale qui a dilaté le royaume originel et éloigné le roi de la Transjurane, notamment au profit de la Provence.

5 Ainsi naît la seconde période, le royaume post-carolingien, marqué par la transformation, sur des rythmes différents, des institutions et des élites. Ces dernières, d'origines diverses, se muent en une aristocratie enracinée, lignagère, puissante et soudée dont le symbole est la révolte de 995. Les optimates forment désormais un groupe reconnu, tandis que sont apparus le premier miles, le premier avoué d'abbaye, les premières traces de seigneuries... L'évolution des élites mais aussi la croissance territoriale, les traditions provençales et l'influence ottonienne, qui placent la monarchie rodolphienne dans une tradition plus royale, conduisent Conrad et Rodolphe III à adapter les institutions. Les souverains s'inspirent alors des solutions germaniques : ils conjuguent politique familiale et politique d'Église royale, privilégiant surtout quelques grands monastères puis l'épiscopat. La politique rodolphienne a aussi ses traits propres. 
Aux grands établissements féminins, les rois de Bourgogne préfèrent une collaboration très étroite avec Cluny; ils recomposent l'aristocratie laïque en favorisant l'implantation de familles allogènes et le développement d'une aristocratie moyenne installée sur des biens publics. C'est seulement dansles années 1020 que Rodolphe III accepte l'émergence de quelques puissants comtes héréditaires, renonçant à s'appuyer sur un épiscopat trop impérial, alors que se profile le rattachement à l'empire. C'est le dernier volet d'une profonde recomposition territoriale qui conserve un fort cadre public. Toutefois, le royaume post-carolingien ne survit pas à la mort d'Henri III en 1056: la disparition du dernier roi couronné en Bourgogne conduit à une indépendance de fait des différents échelons de l'aristocratie et brise le lien entre des espaces fragmentés.

6 Éloignée des grands centres qui définissent et diffusent les schémas de pouvoir, mais située sur un axe majeur, la Bourgogne transjurane est à l'abri de changements radicaux qu'elle n'ignore pas. Les différents modèles politiques ou sociaux voisins trouvent donc leur écho sur les bords du Léman à travers des similitudes avec la Germanie sur le plan institutionnel, avec la France pour l'évolution des élites ou avec l'Italie pour l'importance du caractère public du pouvoir. Comme d'autres régions lotharingiennes, la Transjurane est une terre de transition, mais cette position intermédiaire permet l'essor d'un royaume carolingien tardif puis d'un royaume post-carolingien.

\section{INDEX}

Mots-clés : carolingien, royaume carolingien, élites

Index géographique : Suisse/Léman 